\title{
A Fresh Look at Francesco Severi
}

\section{Judith Goodstein and Donald Babbitt}

A

student of Corrado Segre, Eugenio Bertini, and Federigo Enriques, Francesco Severi is remembered today as one of the key architects of the Italian school of algebraic geometry in the first half of the twentieth century. (For a brief discussion of some of his most important contributions to algebraic geometry, see the appendix.) His eagerness to serve the Fascist regime after Mussolini became dictator in 1925 has cast a long shadow over his name. Even though Severi survived multiple investigations in Italy, rediscovered his Catholic faith, and emphatically denied repeated accusations that he was anti-Semitic, the stigma has persisted.

Among the first, if not the first, to come to Severi's defense in the post-World War II era was Beniamino Segre, who had lost his own academic chair in Bologna in 1938 in the wake of the government's anti-Jewish legislation. Relieved, at Severi's behest, of his duties as an editor of Italy's oldest scientific journal in the wake of the regime's racial laws, Segre nevertheless insisted that rumors of Severi's "supposed anti-Semitism" were "flimsy" and based on "some misunderstanding"

Judith Goodstein is university archivist emeritus at California Institute of Technology. Her email address is jrg@ caltech.edu.

Donald Babbitt is professor of mathematics emeritus at University of California, Los Angeles. His email address is babbitt@math.ucla.edu.

${ }^{1}$ References with an $*$ can be found at the website: http: // www. Judi thGoodstein. com.

DOI: http://dx.doi.org/10.1090/noti881
[Segre 55*]. ${ }^{1}$ Although his tenure as Severi's assistant in Rome from 1927 to 1931 gave him a ringside seat as Severi's politics veered sharply from left to right, Segre took pains to remind Italy's mathematical and scientific communities that his mentor had once championed Italy's parliamentary democracy, protested the brutal 1924 murder of Giacomo Matteotti (a Socialist deputy in Parliament), and signed the philosopher Benedetto Croce's anti-Fascist manifesto-actions that forced his resignation in 1925 as rector of the University of Rome. These events, Segre once said, had led Severi to have "a profound disagreement with the fascist government, which lastedif even in a form increasingly attenuated-for several years, even after having been called to take part in the Academy of Italy" [Segre 63*]. And, on that sober note, Segre took leave of Severi's political career under Mussolini.

Our story offers a fuller look at Severi's political dossier during the inter-war years and beyond. Primary sources range from the personal correspondence of Beniamino Segre and Oscar Zariski to Italian government records of the Fascist period in the Archivio Centrale dello Stato (ACS) to documents in the historical archives of the University of Rome and the Lincei. The whereabouts of Severi's personal papers is a mystery, and it is possible that he destroyed them. Some mathematicians may find a recounting of his activities under Fascism uncalled for, preferring to recall only his considerable mathematical legacy. (Again, see the appendix for a nontechnical discussion of some of the most important parts of this legacy.) Others 


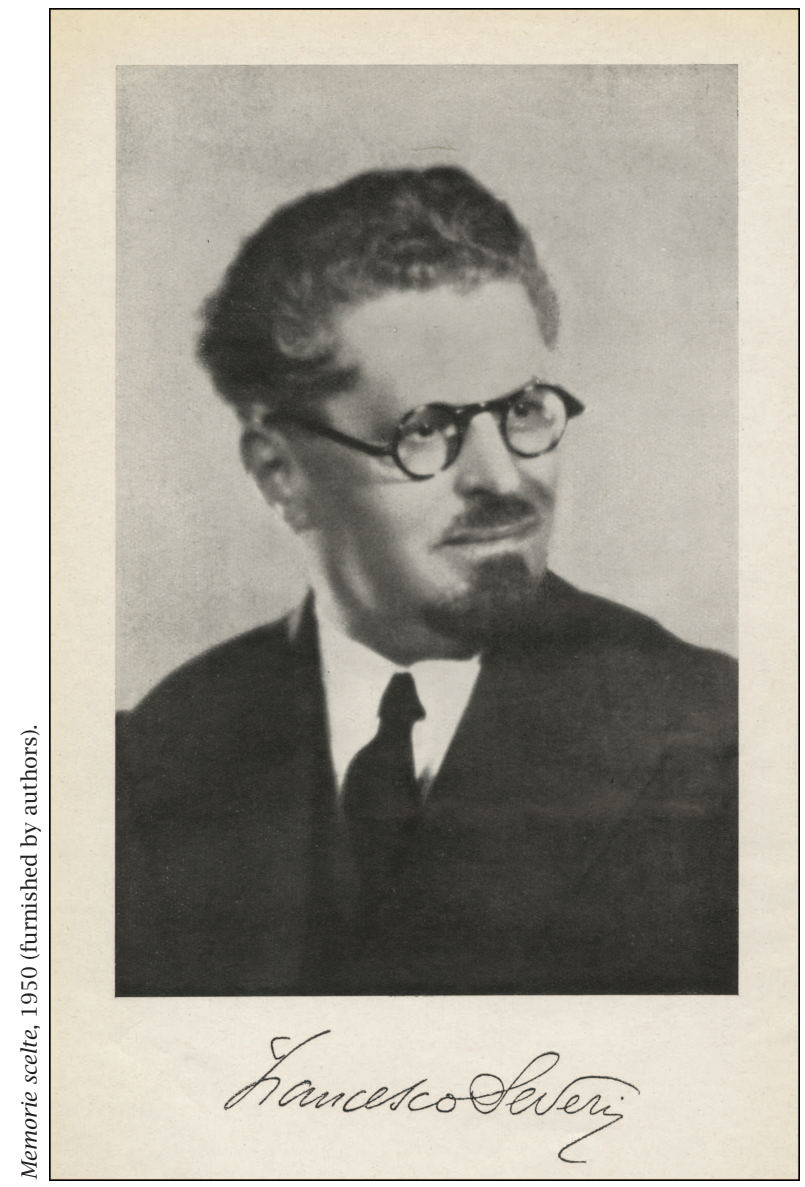

To celebrate fifty years of publishing activity, Severi offered Zanichelli, the publishing house with close ties to Federigo Enriques, the opportunity to publish his collected works, in multiple volumes. When Zanichelli said no, Severi enlisted Beniamino Segre's help in preparing a selection of his writings instead. Severi chose this picture of himself for the frontispiece, but asked Segre to remove the fascist insignia first.

are content to allow the proverbial skeletons in the closet to remain undisturbed.

In 1989 the Italian geometer Edoardo Vesentini raised the subject himself in a talk at the Accademia dei Lincei, which hosted a one-day meeting on the cultural consequences of the racial laws in Italy. Speaking about his own discipline, Vesentini said, "Even if we all know that closets exist and skeletons also, forgotten or hidden, and [even] if we all know that such recognition cannot be deferred indefinitely" [Ves 90], the thought of taking his own teachers and the more senior members of the Italian mathematical community to task fifty years after the Fascist regime issued its Manifesto of Italian Racism seemed unduly harsh. Some colleagues had only recently died, and remembering them, he told the group, brought back memories along with "a mixture of admiration and, sometimes, affection." Fortunately, the mathematicians of his own generation, those who came of age after 1945, had at least "been spared the shame of being among those mathematicians" who had been forced to tell Castelnuovo and Enriques (two Jewish mathematicians) they could not enter their institution's math library. Castelnuovo's lack of bitterness after the war ended, Vesentini noted, had played a crucial role in putting the country's mathematics back on track. "The generosity and far-sightedness of Castelnuovo," he added, "must not prevent, above all, the events of those years from being investigated and thoroughly examined ... because those events belong to the history of science."

\section{A Taste for Politics}

Born in 1879 the youngest of nine children, Francesco Severi grew up in poverty in the Tuscan town of Arezzo, where as a boy he took a keen interest in politics, following in particular the socialist movement, then on the rise in Italy. After being appointed professor of mathematics at Padua in 1905, Severi allied himself with the left-wing blocco popolare patavino, which rewarded his allegiance by appointing him president of the municipal gas and water company. In 1910 he officially joined the Socialist Party and was quickly elected councilor for the commune of Padua and became the Socialist alderman for education. When World War I broke out, Severi sided with those who urged intervention on the side of Britain and France. He severed connections with the Socialist Party, which supported Italian neutrality, and quickly volunteered for military service once Italy entered on the Allied side in 1915.

Between 1918 and 1925 Severi flirted with running for political office and received backing from war veterans and Socialist-run unions. He served for a time as president of the newly formed National Association of University Professors and became rector of the University of Rome on the recommendation of Giovanni Gentile, ${ }^{1}$ who at the time was enjoying a brief tenure as minister of public instruction. It is not entirely clear how Severi's association with Gentile, a philosopher and leading proponent of fascist ideology, may have affected his views. However, several years after Mussolini's

\footnotetext{
${ }^{1}$ An ardent supporter of the fascist government and a major figure in Italian philosophical circles, Gentile implemented far-reaching and lasting educational reforms during his time as minister of education (1922-1924). Often referred to as "the philosopher of fascism", he wrote several key political tracts for Mussolini, including "The Manifesto of the Fascist Intellectuals", which many leading fascist writers and artists signed in 1925.
} 


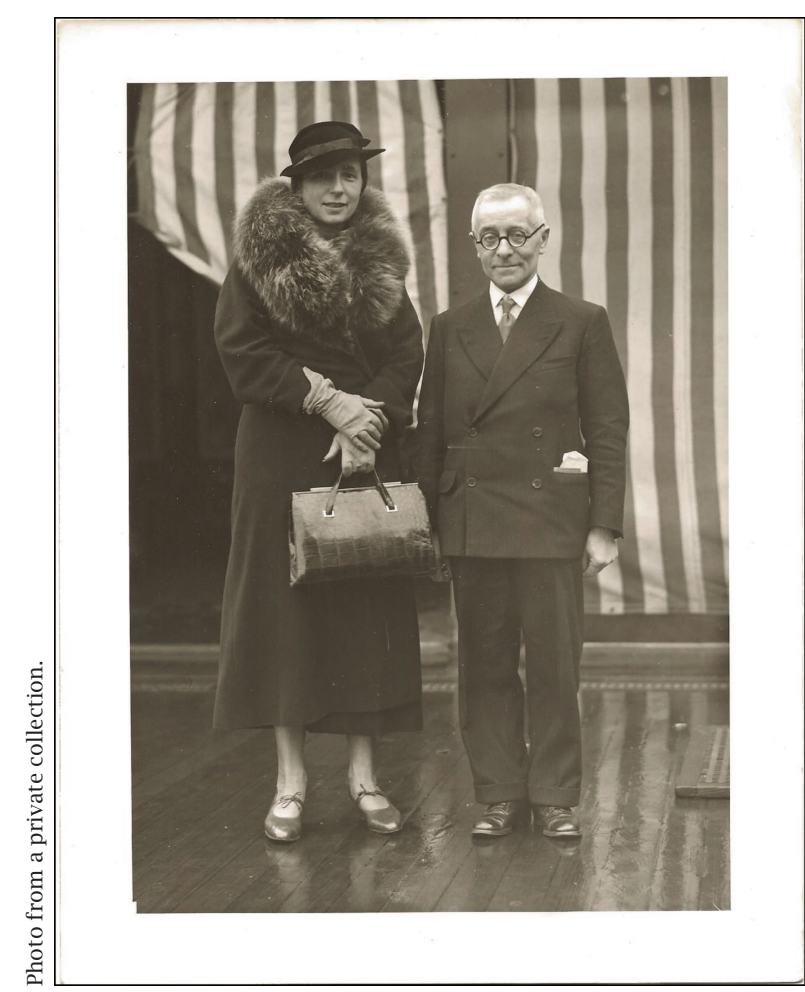

Tullio Levi-Civita and his wife Libera Trevisani, one of his pupils at Padua, whom he married in 1914, celebrate their arrival in New York City, 1933.

1925 proclamation of a dictatorship - "We are not a ministry; we are not even a government. We are a regime" [Bo 05], Il Duce (Mussolini's title for himself as "chief" of the fascist movement) told the deputies in Parliament in the spring of that year-Severi began sending the Fascist leader a steady stream of articles, several embellished with a flowery personal note. Taking his lead from Mussolini's own political trajectory (Il Duce had started his political career as a socialist), Severi appears to have cast off his socialist political ties when they no longer suited his political ambitions. Although he later wrote that his act of defiance in speaking out against Matteotti's political assassination in 1924 had ended forever "his active participation in political life" [Sev 45*], the historical record suggests that he wanted to play a prominent role in the intellectual life of the new fascist state. Indeed, Severi used his considerable political connections to promote his advancement.

\section{The Accademia d'Italia}

Plans for a new state-sponsored cultural institution, the Reale Accademia d'Italia (The Royal Academy of Italy) began to take shape in 1926, and Severi took a keen interest in the slot reserved for a mathematician. It was an open secret that another algebraic geometer from Rome, Federigo Enriques, born into an Italian Jewish family, had been nominated. That Severi had been feuding with Enriques for several years over a satisfactory algebro-geometric proof of the "Completeness Theorem" (see [B-G 10]) and other matters only heightened the stakes for Severi.

The more he thought about his own political future, the more Severi seems to have become convinced that a Fascist loyalty oath was the answer. Speaking, he said, on behalf of "the great majority" of professors, in January 1929 Severi dispatched an unsolicited and impassioned memo to Mussolini himself, urging swift passage of an oath that would serve to indemnify those who, like himself, had engaged in "nonorthodox demonstrations," such as signing Croce's manifesto. Anything short of that, he added, would "deprive our Universities of most of the best mathematicians. On the faculty at Rome, almost none perhaps would remain." ${ }^{2}$ Rest assured, Severi continued, "I have never done anything or criticized anyone that could even remotely be interpreted as contrary to the Regime" while abroad [G-N 05]. Although Severi had not yet become a party member (he joined the Fascist Party in 1932), he had begun to ingratiate himself with Benito Mussolini's regime.

In mid-February, Severi enlisted his university colleague and confidant Giovanni Gentile, no longer minister of public instruction, in his political aspirations. Less emotional, more practical in tone, Severi's letter to Gentile began by reiterating that Italy badly needed a loyalty oath to identify and isolate university professors hostile to the Fascist regime and to reward those, like himself, who had resolved their differences with Mussolini's government. "As I already told you in person," he reminded Gentile, "within the limits of my own poor powers, I have done as much as I could for this purpose, and I have reason to think that the Head of Government is very well disposed." He then went on to instruct Gentile at length about how to manage the other stakeholders in the matter, including the press, the fascist rank-and-file, and various ministries, and what they should and should not be told. Only in a

\footnotetext{
${ }^{2}$ The loyalty oath required of all university professors was administered two years later in 1931. Twelve courageous academicians out of 1,250 refused to sign and lost their university posts, including Vito Volterra, the undisputed head of Italy's school of mathematics before the advent of Fascism. Relations between Severi and Volterra had always been rocky, helped along by the fact that Volterra, an avowed anti-Fascist, had once said to him during a session at the Lincei, "Algebraic geometry serves no purpose" [Tri $67 *$.
} 
brief postscript, in which Severi informed Gentile that he had marginally patched up a long-standing quarrel with Enriques over competing textbooks ("but with open [and] utter disgust"), did he mention that Enriques's Academy nomination might be in trouble [G-N 93*]. Gentile's response to this letter, if there was one, has not survived.

Whether by design or chance, Severi had landed in the right spot if things veered off track for Enriques, which they did. In mid-March, barely one month later, the government deleted Enriques's name from the list of candidates sent to the president-elect of the Academy of Italy. In its place appeared the name Severi. Recalling that period at Rome, Giorgio Levi della Vida, at the time director of the Oriental School, wrote, "The Rector then was Francesco Severi, a great mathematician and an energetic man of action ... whose antifascism could not resist the seduction of the [Royal] Academy of Italy, and as the first error leads to a second one easily and a third, [the error] turned into enthusiastic support for the regime" [LeviV 66*].

One of the many congratulatory telegrams Severi received in 1929 following the government's public announcement of his nomination came from the differential geometer Tullio Levi-Civita, a colleague at the University of Rome and one of Italy's most distinguished mathematicians. In response, Severi sent Levi-Civita, his friend of more than twenty years, a letter marked "confidential" from Barcelona, where he was lecturing. He expressed "absolute surprise" at his own nomination and remorse over the omission of Levi-Civita's name. "I certainly would have loved to see you, the strongest among the columns of Italian mathematics, in the Academy also," he wrote. "Let us trust in the future" [Sev 29*], a veiled hint perhaps that Severi intended to nominate his friend. Later that year, in fact, when Severi raised the issue with his Jewish colleague, Levi-Civita reminded him in writing of the obstacles ("two distinct objections, stated or implied”) standing in his way: politics and religion. As the historian Annalisa Capristo, who has written extensively about the exclusion of Jews from Italian academies before and after the racial laws, writes, "In fact, we have no knowledge of other possible 'objections.' On these delicate questions, however, the two correspondents maintained-at least in their exchange of letters - an understandable discretion" [Cap 03].

The Vatican acted first. In February 1929, Mussolini's government and the Vatican had signed the Lateran Accords, each recognizing the other's sovereignty as a state, and in April 1929, only a month after the Reale Accademia d'Italia announced its first thirty members, the Vatican's Accademia Pontificia delle Scienze elected LeviCivita and the world-renowned mathematician
Vito Volterra, both born into Jewish families, members of its group. Anti-fascist organizations had been quick to note the absence of any Italian Jews among the first members of Mussolini's Academy, and in fact the fascist academy was never to admit any Jews to its ranks [Good 84]. The Vatican simply leveled the playing field.

That October the thirty successful candidates for the Royal Academy of Italy, including the physicist Enrico Fermi, the composer Pietro Mascagni, and Francesco Severi, the sole mathematician, gathered in the Campidoglio, Rome's city hall, where Prince Francesco Boncompagni Ludovisi, the city's governor, proclaimed them the aristocracy of Italy's intelligentsia. Clad in a ceremonial suit embroidered in gold, a stipend of 3,000 lira a month lining his pocket, and promoted to the rank of "your Excellency", Severi had been appointed the regime's spokesman for Italian mathematicsand in the eyes of Italy's new rulers, he was. As one of Severi's assistants in Rome, Francesco Tricomi, the author of a classic text on integral equations, later recalled, Severi was as "exuberantly fascist as he had earlier been antifascist-who wanted to be and to a certain extent, was - the 'boss' of Italian mathematics in the fascist period" [Tri 67*].

Severi proceeded to play an active role in the affairs of the fascist academy. Besides diligently attending sessions, he nominated candidates for membership, including Levi-Civita in 1933 and again in 1934, although both he and Levi-Civita knew of the insurmountable obstacles other Jewish candidates had faced. In addition to serving on various commissions, including one charged with purifying the Italian language of foreign words (e.g. cocktail), he presented numerous papers, his own and others'; and, indeed, when called to account for his activities later, he proudly noted that he had personally introduced thirteen of the fourteen papers authored by Jewish scientists. However, in 1931, when Mussolini, with the complicity of Academy president Guglielmo Marconi, intervened decisively to prevent the Academy from awarding the first Mussolini Prize in science to the militantly anti-fascist and Jewish professor of human anatomy Giuseppe Levi, Severi did not speak up in defense of Levi, nor did he voice any objection to the government for not following its own rules [Fabre 08]. (The honor of receiving the first Mussolini Prize went to a well-knownand Christian-physiologist and explorer in good standing with the regime, Filippo de Filippi.)

\section{Severi's Interactions with Colleagues}

In his dealings with others, Severi often came across as arrogant, autocratic, and quick to take offense. There seemed to be no middle ground: he either dazzled those around him ("Severi is a man 
with bewitching hands, when he does something, it is always splendid" [ScorD 62*], the Sicilian mathematician Gaetano Scorza once remarked) or demonstrated "a childlike incapacity either for self-criticism or for cool judgment," as Leonard Roth, the English algebraic geometer who spent the year 1930-1931 in Rome, famously observed. Worse still, Roth added, "he meddled in politics, whereas it would have been far better had he left them alone" [Roth 63].

Mathematical collaborations with Severi could also be challenging, recalled Scorza's son, Giuseppe Scorza Dragoni, who collaborated with Severi on the second and third volumes of Lezioni di Analisi, magisterial tomes, published in 1942 and 1951. As the younger Scorza recounted in a letter to Segre after Severi's death, some of the difficulties arose because the Tuscan mathematician always had a hundred different obligations to attend to. In fact, he had once spent his entire vacation in Rome without being able to meet with Severi once, except on the last day. Scorza also quickly learned that Severi would not admit to making any mistakes. "But this last obstacle, when I realized it," Scorza continued, "I got around easily: instead of saying where there was a mistake, and how it should be fixed, I pretended to not understand and I continued to not understand until Severi, furious by my artfully directed objections and questions, ended by finding the mistakes and [making] the corrections himself" [ScorD 62*].

Severi believed, according to Roth, "that the world at large failed to treat him with due consideration. For, incredible as it may seem, although during the whole period of his maturity honours were showered upon him and invitations poured in, yet he remained forever unsatiated ...he seemed more or less permanently aggrieved" [Roth 63].

Severi's trip in 1930 to South America is a case in point. During his stay there he gave a series of technical lectures to a university crowd in Buenos Aires, telling his audience in so many words, according to one listener, that he had come to Argentina "to civilize and teach mathematics" to the country's inhabitants. He also ostentatiously announced in several lectures that he disagreed with Levi-Civita "from several points of view." Severi's pronouncements did not sit well with the mathematicians in the audience, who knew of LeviCivita's pioneering work in differential geometry and admired it. Severi further enraged his hosts by asking point-blank, "If you have made [French mathematician Jacques] Hadamard and Enriques academicians [of Argentina's scientific society, the Sociedad Cientifica Argentina], why haven't you done the same for me?" With the society's members deeply divided over what to make of Severi's mathematical reputation, they postponed the decision on his election until they could learn more about him as a person. The task was entrusted to an old classmate of Levi-Civita's, Felix Carli, a member of both the Sociedad Cientifica Argentina and the Accademia di Scienze Fisiche e Matematiche di Buenos Aires. "I beg you to give me your opinion of the man" [Carli 30*], he wrote to LeviCivita. While we lack Levi-Civita's reply, Severi's substantial list of honors and affiliations does not include membership in either of Argentina's scientific organizations, which may suggest a tepid response on Levi-Civita's part.

Serving as Severi's assistant for four years, Francesco Tricomi, like Roth, had ready answers for those wanting to know what he had experienced in Rome. As a professor and mentor, he reported, Severi knew how to push his students along; on the pedagogic side, he ranked as an extraordinary teacher, and Tricomi had found his classroom duties useful, unlike Severi's other assistants who considered them a "waste of time". However, Tricomi also thought that Severi behaved as if he was "the 'padrone' [the lord and master], a little overbearing....[although] I never had any real clash with him," which Tricomi attributed to treating his responsibilities as an extension of his recent military service. Later, when Tricomi moved up the academic ladder and became a professor of mathematics at Florence, he took less kindly to Severi's requests, reminding him, politely but firmly, that "I was no longer under his orders" [Tri $67^{*}$ ].

Beniamino Segre, who became Severi's assistant several years later and who remained closer to him than any of his other pupils, also remembered him as "ambitious and pugnacious" [Segre 62]. Straining after the events of World War II to paint an accurate and fair portrait of Severi as a man, Segre said, "We need to keep in mind that Severi had a complex, intense, tormented nature, and an exceptional personality," which Severi himself had described as a "restless energy, which takes away my breath and makes me unhappy" [Segre 63*]. All in all, Segre concluded, the appearance of fearless confidence that Severi projected probably concealed some "mysterious, unjustified fear of not being appreciated and loved." Recalling his own dealings with Severi in Rome in the early 1920s, the American mathematician Oscar Zariski told an interviewer that Severi once said to him, "I love you, Zariski, but you don't love me" [Parikh 91], although the correspondence between the two mathematicians after the war suggests a more complicated relationship. 


\section{Public Acts}

Unlike Enrico Fermi, his colleague at Rome, who never talked politics, Severi actively cooperated with Mussolini's government. In an article aptly titled "Fascismo e Scienza", published in 1933 in L'Illustrazione Italiana, a popular weekly magazine, Severi dismissed those who remained mired in the past ("a wretched preoccupation with conventional analytical politics and trifling doctrines from other times") while extolling, in the name of patriotism, loyalty to the regime for its goal of restoring the grandeur of Rome and reclaiming Italy's place in the world of science, starting with mathematics [Sev 33*]. The Italian school of mathematics was a matter of deep national and personal pride for Severi, who told his readers: "Not everyone knows that...Italy, in fact, occupies one of the foremost places, if not the first, in mathematics in the world today. Foreign mathematicians everywhere," he continued, "recognize this and as Italians and as fascists we are legitimately bound to be proud of it." More importantly, he concluded, "we export many ideas, nay many more than those we import." Even after the war ended, Severi persisted in believing that Italian mathematics (and by extension, his own achievements) did not receive the recognition they deserved outside Italy. ${ }^{3}$ "Thank you for the draft ...of [Fabio] Conforto's review," Severi began one letter to Ralph Boas, executive editor of the Mathematical Reviews, in March of 1949,

I note, however, that the last lines of the original review, which had expressed a sensible opinion of my work, have been deleted. I would not point this out if I had not been very hurt by the way my works are generally reviewed in MR. This is the first time, after a half-century of intense, nonstop work in science, that I find myself having to express such grievances to a publication. Publishing ...Conforto's final comments would perhaps have served to reaffirm that the Directors of MR do not share the unfavorable attitude of certain reviewers, which is something you kindly mentioned to me and which I certainly believe....In any case, in your position...you have connections with many mathematicians and frequent opportunities to bring people together. Therefore I have faith in your efforts to restore the reputation of Italian mathematics, which is alive and active....As one [who] loves my country and

\footnotetext{
${ }^{3}$ Nor, for that matter, does the recent authoritative reference treatise The Princeton Companion to Mathematics [Gowers 08] cite the contributions of the Italian school of algebraic geometers by name.
}

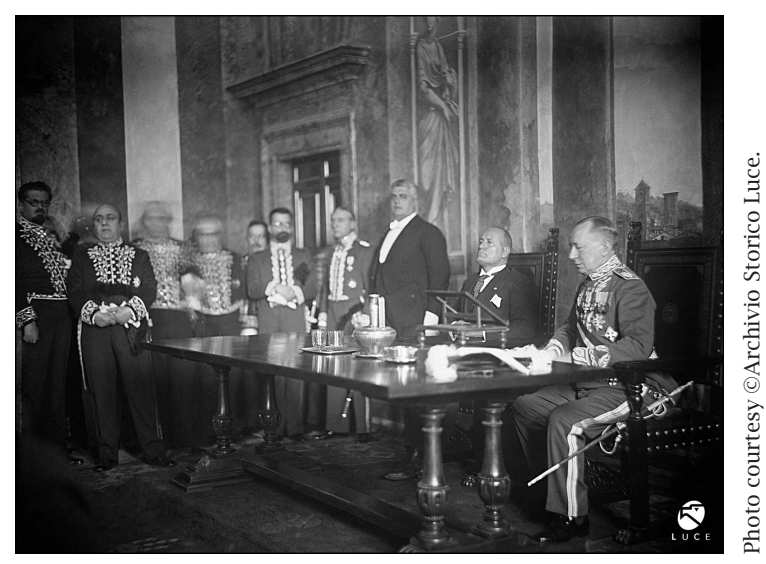

Inaugural session of the fascist Academy of Italy, Farnesina Palace, 1930. Guglielmo Marconi, in ceremonial uniform, is seated next to Mussolini. Other academicians gathered around the table include Francesco Severi, Cesare Bazzani (first and second from left), and Francesco Giordani (third from right).

my science...this would distress me greatly, and if I am induced to do something that costs me some sacrifice (no one likes to talk about himself), it is because I believe I have to do it not so much in my own interest as in defense of my School, which follows me faithfully and which, like the majority of Italians, is working to restore our country, after the great disaster, to a high international level in the intellectual and spiritual realm, which is the realm where Italy has always distinguished itself throughout the centuries. [Sev 49*]

Enacted in 1938, Italy's anti-Jewish legislation altered abruptly Segre's relationship with Severi. "You already know of the whirlwinds that have shocked us over the past several months, inflicting unspeakable moral pain on us," Segre wrote to Zariski from Bologna on October 16, the day after the racial laws had banished him from the classroom, expelled him from numerous scientific academies and organizations, and relieved him of his duties as a managing editor of Annali di Matematica Pura ed Applicata [Segre 38*]. "Still more distressing," he added, "is the apathetic-if not to say hostile-attitude of certain individuals of our common acquaintance," being careful not to mention anyone by name. That same day, Segre sent a letter to Levi-Civita, also a member of the journal's editorial board, in which he identified Severi as the chief instigator behind their dismissal. In it, he wrote: "The initiative was started by S[everi], who-some time ago-indicated to the President of the [organization unidentified] the situation in the editorial office of the Annali. Said 
President then wrote to Dr. [unidentified name], requesting advice and this person left the matter completely up to Severi's decision" [N 96*]. Of the journal's four editors, three were Jewish (Guido Fubini was also dismissed), leaving Severi, who had joined the editorial board in 1925, as the journal's sole editor. "In no other case up to now has anything similar happened," he told LeviCivita. Recalling the event in an article dedicated to Giovanni Sansone and published many years later in the Annali, Severi noted the "deplorable decree" that left him remaining "alone on the scientific committee of the 'Annali', becoming automatically, without my desire, the only managing editor" [Sev 60]. His colleague Giovanni Sansone, added Severi, had been the very first to share with him the duties of running the journal.

When the publisher of Springer ordered its editor, Otto Neugebauer, ${ }^{4}$ in 1938 to remove Levi-Civita's name from the masthead of the Zentralblatt, the renowned international review journal in mathematics founded by Neugebauer, on the grounds that according to Italy's racial laws he was no longer a university professor, Severi's name quickly appeared in his place. While planning for the second meeting of the Italian Mathematical Union in Bologna in 1940, the organizers debated whether Levi-Civita, a former member and an expert on general relativity theory, could be invited to speak on that topic as a guest. Severi is reported to have said, "Please! We just got rid of that race." The historians of Italian mathematics Giorgio Israel and Pietro Nastasi, who have written extensively about science and race in fascist Italy, have also reported that Severi personally intervened to deny his Jewish colleagues access to the University of Rome's mathematics library after the racial laws went into effect. ${ }^{6}$ Two years later, Severi wrote Levi-Civita a friendly, if short, note in which he apologized for not being able to personally deliver a recent issue of the Annali, "but since I see that it is late, I am sending it to you,

\footnotetext{
${ }^{4}$ Neugebauer subsequently resigned from all editorial duties at Springer journals, left Germany, and joined the Brown faculty in 1939, where he became the founding editor of the AMS's new abstracting journal, MR (Mathematical Reviews).

5 "Per carità, ci siamo appena liberati di quella razza." The story has been passed down from the mathematician Ugo Amaldi, present at the meeting, to Edoardo Amaldi, his son, who played a central role in rebuilding Italian physics after World War II, to Edoardo Vesentini, a distinguished algebraic geometer in his own right and former president of the Lincei, private communication, Tullio G. Ceccherini-Silberstein to the author (JG), November 11, 2011.

${ }^{6}$ Enzio Martinelli, a pupil of Severi, is the principal source for this story, private communication, Giorgio Israel to the author (JG), Oct. 28, 2011.
}

reserving to myself to come and greet you as soon as it will be possible for me" [Sev 40*]. History does not reveal if Severi kept the appointment.

By the end of the decade, Severi had consolidated his leadership position within Italy's mathematical community. In spring 1938, Severi petitioned Mussolini to underwrite an Institute of Higher Mathematics in Rome [INDAM], which was inaugurated in 1940, with the Duce; the minister for national education, Giuseppe Bottai; and a host of other Fascist dignitaries in attendance. Not surprisingly, Severi also became the institute's first president. In the wake of the racial laws, he had succeeded Enriques as professor of higher geometry at the University of Rome; he had also replaced Enriques as director of Rome's school of post graduate studies in the history of science. One of the few items still missing from his lengthy list of honors and appointments was membership in the Pontifical Academy of Sciences, whose roster had recently expanded to include Robert Millikan, Max Planck, Erwin Schrödinger, and other notable scientists. In 1939 an opening occurred. As one of four scientists in the running for the one vacant seat, Severi's credentials were hard to top. As one academy member wrote to Caltech's Millikan, highlighting the advantages that Severi's election would confer on the Pontifical Academy, "[W]e all have a great interest in concentrating our designation on the name of H[is] E[xcellency], Professor Severi, not only because he is a prince among the mathematicians, and probably the most prominent in the world in the branch of algebraic geometry...but on account of his great authority and his political position in Italy, we are in need of his help as a friendly link between the Italian authorities and the Pontifical Academy" [Giorgi 39*]. One wonders if Severi, who won the election, appreciated the irony of listening to papers presented by its long-time members Levi-Civita and Vito Volterra, both of whom had paid dearly for being both Jews and anti-fascists in Mussolini's Italy.

\section{Investigation and Rehabilitation}

After the liberation of Rome in June 1944, Italy's newly installed provisional government established a High Commission for Sanctions against Fascism to investigate allegations of wartime collaboration against party members, either for taking an active part in Fascist political life or for remaining loyal to Mussolini after he was deposed in September 1943. That year, at the behest of the Ministry of Public Instruction, the commission took up the case against Severi, the only mathematician dealt with in this fashion. When it initially suspended him from university teaching, 
effective August 1, 1944, Severi appealed the ruling. To the charge that he had been an apologist for the regime during the war, Severi countered by saying that he'd given scientific talks in Spain and Portugal, not political speeches, and that he had made a 1943 trip to Germany for the sole purpose of collecting a medal in connection with a Copernican anniversary. In May 1945, Severi's suspension was annulled and replaced by a sanzioni minori, a simple censure that involved a letter placed in his university personnel file, but that did not prevent him from teaching a course on higher geometry at INDAM during the 1945-46 academic year [Rog 05].

When pressed on the issue of anti-Semitism, Severi pointed to his repeated efforts on behalf of Levi-Civita (who had died in 1941) for membership in the Academy of Italy [Cap 03] and his continued friendship with Segre, whom he described as having always been his favorite student. Neither the central commission nor a separate commission assigned in 1945 to examine the behavior of former members of the Academy of Italy found anything to condemn in Severi's personal or professional conduct. In its report on Severi's conduct, in fact, the commission noted: "The moral rectitude and good services of [P]rofessor Severi as a person and as a scientist are beyond discussion and on the other hand no one could doubt it" [ACS 45*]. Faced with a new investigation the following year involving former Fascist academicians, Severi told Segre, "Naturally, I'll come out from this painful trial as immaculate as I have always been" [Sev 46*].

Severi's prediction proved true but only up to a point. In 1945 a separate committee, appointed by the provisional government to reconstitute Italy's storied Academy of the Lincei, homed in on members who had belonged to the Academy of Italy. The chairman of that commission went out of his way to note that the range of Severi's activities demonstrated "a marked independence and courageous conduct to ensure that science prevailed over the dominant politics" [ACS 45*]. In so many words, as the central commission had previously concluded, Severi "had not received from Fascism anything more than was his due as a distinguished scientist." Nevertheless, that summer the committee members unanimously decided to purge from the Lincei any members who had taken part in a March 1944 meeting held in German-occupied Florence, regardless of the reason behind their attendance. Severi had been present at that meeting, and so he was out. As Guido Castelnuovo, a committee member and Jewish mathematician who had gone into hiding during the war, wrote to Severi that June, "It pains me that it is necessary to take a step of such a nature with respect to a scientist who has honored Italy such as you" [Cast 45*].

According to the commission, Severi's transgression had been to accept an invitation from his old friend Gentile, at the time the Academy of Italy president, to attend a celebration there in honor of the eighteenth-century political philosopher Gianbattista Vico. "I have no reason to correct any page from the book of my life," Severi replied, after reading Castelnuovo's letter [Sev 45*]. Far from admitting any wrongdoing, Severi defended his visit, but thought it important to add a postscript in which he pointed out that "among the important examples of his behavior with respect to the racial laws," he had seen to it that Castelnuovo's book on the origins of the calculus remained in circulation after 1938.

Gentile was unavailable to shed any further light on the matter, having been assassinated by communists in Florence in August 1944 while riding his bicycle. Four years later, Italy's minister of justice, Palmiro Togliatti, declared a sweeping amnesty, and in July 1948, Severi was reelected a member of the Lincei. Severi, who had lost his position as president of INDAM, also recovered that post following the amnesty and held it until his death.

Although Severi emphatically denied being antiSemitic at the end of the war, he saw evidence of others "paint[ing] me, especially in the AngloSaxon world, as anti-Semitic...[and presuming] racial preconceptions that I have never had," he wrote in one letter to Segre [Sev 49*], adding, "And you and many other Israelites know this well." A case in point was Oscar Zariski, ${ }^{7}$ born into a Russian-Jewish family and an algebraic geometer at Harvard, who seemed in no rush to resume contact with Severi after 1945. "I am very sorry that he didn't answer [my letter]," Severi told Segre,

I had sent him [in 1948] many of my papers including books, together with a very warm letter...I did the same with [Solomon] Lefschetz, who has already answered...expressing his deep appreciation. No answer, instead from Zariski, to whom I won't send anything more from now on, unless things

\footnotetext{
${ }^{7}$ Zariski attended high school in Chernigov (Ukraine) and the University of Kiev (1918-1920). Admitted to the University of Rome in 1921 as a third-year student, Zariski received his doctor's degree in 1924 under the supervision of Castelnuovo. Zariski later said that Castelnuovo chose a problem that would suit him (Galois theory, solving by radicals) because he could see that Zariski was not, at heart, a geometer in the sense of the Italian school of algebraic geometry. He did postgraduate work at Rome on a Rockefeller fellowship (1924-1926) before going to Johns Hopkins University in 1927.
} 
change. I know that Zariski had a grudge [against me]; [Tomás Rodriquez] Bachiller, who was there [at Harvard] ...wrote to me that he had...explained to Zariski the real facts and that he seemed to be persuaded.

Does he still perhaps believe in my antiSemitism, the most disgusting calumny that has been circulated underground, without ever having the bravery to pronounce it publicly, it being so far from the truth? Why would he keep considering the polemics I had with Enriques in the past as a display of anti-Semitism? Can't anyone have a bone to pick with a Muslim without being against Mohammed. [Sev48*]

Severi also felt that these accusations had done great damage to the reputation of his own field of mathematics. As he wrote to Segre in another letter, "The attack that has been conducted against me has ended by damaging Italian geometry abroad and especially in America [Sev 49*]. You have only to look, continued Severi, at the "very hostile attitude towards us" by Zariski's group of abstract algebraists, despite the fact that Zariski "formed his outlook (that I always guided) in Italy."

Severi also found that some French mathematicians continued to harbor hard feelings toward him in the postwar period. Mounting a spirited defense of his aging mentor, in 1955 Segre wrote a letter to the French mathematician René Garnier, in which he stated unequivocally that rumors of Severi's anti-Semitism did not square with what he knew. In the paragraphs that followed, Segre reiterated many of the arguments Severi had used in the past to defend himself, including Segre's own interactions with Severi. In his reply, Garnier said that he was personally satisfied by Segre's narrative, but others might not be, given that "in Paris, there is strong resistance" [Ga 55*].

There is little correspondence between Severi and Zariski in Zariski's papers, which are deposited in the Harvard University Archives. There is none from before World War II, and the few letters they exchanged after 1948, when the correspondence seems to have resumed, at times turned testy. In response to a letter written by Zariski in summer 1953, Severi demanded to know why Zariski had brought up Hitler and Mussolini: "Do I have perhaps some responsibility in front of those who had to flee from paradise from the first and did not find asylum in the second?...Your references demonstrate to me that in certain areas of the mathematical world this non benevolent attitude towards me, from which I have greatly suffered, has not ceased.... On your part I have often had an impression of coldness, which at times I was not expecting. But it could be that it is only a consequence of your temperament" [Sev 53*]. Severi then turned to mathematical matters. Judging from their later correspondence, the subject never came up again.

One year later, when Severi's name was pointedly omitted from the list of speakers for an international symposium on algebraic geometry in 1954, Zariski wrote to the chair of the organizing committee: "I am particularly worried about the omission of the name of Severi. I think that Severi deserves a place of honor in any gathering of algebraic geometers as long as he is able and willing to attend such a meeting. We must try to avoid hurting the feelings of a man who has done so much for algebraic geometry" [Zar 54*]. An invitation was duly issued to Severi. ${ }^{8}$

Severi died in Rome on December 8, 1961, at the age of eighty-two; he remained proud of the fact that, as he once wrote, "I have never recanted nor repudiated any of the acts of my life that were, and are, expressions of the strongest attachment to my country" [Sev 53*].

\section{Appendix: Severi the Mathematician}

Francesco Severi, who contributed in fundamental ways to several areas of mathematics in the first half of the twentieth century, is generally acknowledged as one of the three great Italian algebraic geometers of that era, together with Guido Castelnuovo and Federigo Enriques. A hugely prolific author, Severi's bibliography contains 415 items, including 34 books that range from elementary to advanced monographs. He was gifted with extraordinary geometric intuition; however, when this was combined with the Italian algebraic geometers' imprecise mathematical language and their notion of what they considered a proof, it led him many times to either state a true theorem for which it was impossible to convert his proof to an acceptable modern one (e.g., see the article of Joseph Harris [Ha 86]), or to state as a true theorem one that was "almost true" but which later mathematicians had to modify in order to obtain a true theorem (e.g., see the article by Robert Lazarsfeld [Laz 81]). Ironically, Severi's own ideas in another context have often been utilized to furnish the correct proofs. For an authoritative discussion of Italian algebraic geometry and algebraic geometers, including Severi, between the two world wars, see the book by Aldo Brigaglia and Ciro Ciliberto [B-C 95].

In 1949 Severi presented a paper at the Colloque de géométrie algébrique, held in Liège [Sev 49], entitled "La géométrie algébrique italienne: sa rigueur, ses méthodes, ses problèmes". In it he

\footnotetext{
${ }^{8}$ It was at this symposium where the famous exchange with André Weil took place (see next page).
} 
defended the Italian approach to what constituted a satisfactory proof. Here are two samples of what Severi had to say. In his opening paragraph he writes: "For many years a legend has run through a certain part, fortunately limited, of the mathematical community that Italian algebraic geometry, while being ingenious and rich in important results, has not yet attained the necessary rigor". He then goes on to discuss "substantial rigor", i.e., the sense of rigor of the Italian school, and "formal rigor," i.e., the sense of rigor of the Franco-American school of André Weil and Oscar Zariski.

Later in his talk (p. 41), while discussing a recent letter from "an eminent foreign geometer" (not named, but almost certainly Zariski), he says: "Personally, I believe that our methods, when carefully analyzed, give the same sense of assurance as the purely algebraic methods." Here by "algebraic methods" he seems to be referring to the Franco-American school's methods of proof. For the response of the "formal proof" community, see the critical and very interesting review of this paper by Claude Chevalley in Mathematical Reviews, 1951 [MR 0038094; 12, 353f].

What might be correct to say is that Severi, perhaps more than any other major mathematician of his day, stated more true theorems whose proofs were "irreparable" by modern standards or "almost true" theorems that required modifications to make them true or that were just plain false "theorems". But sorting through his triumphs and missteps is a story for another day.

\section{Some of Severi's Main Contributions to Algebraic Geometry}

Theorem of the Base. Severi's most cited work is almost certainly his Theorem of the Base, which he proved early in his career and is now usually referred to as the Néron-Severi Theorem [Sev 06].

It was one of the major results of early twentieth century algebraic geometry over the complex numbers $\mathbf{C}$, and the paper itself was explicitly solicited for the Math. Annalen by Max Noether. The theorem says that a certain important abelian group NS $(F)$ naturally associated with an algebraic surface $F$ over $C$ is finitely generated. Specifically, $\mathrm{NS}(F)$ is the quotient of the free group generated by the irreducible curves (divisors) on $F$ by the subgroup of divisors algebraically equivalent to the zero divisor. Néron [Ner 52] showed that the theorem also holds for surfaces over any field, which is the reason that his name is also attached to it. For more detail on the theorem and Severi's contribution, see [Zar 71, Ch. 5.6].

Contribution to the Proof of the Fundamental Theorem of Smooth Surfaces over C. Both Severi [Sev 05] and Castelnuovo made related and key contributions to the proof of the Fundamental Theorem of Smooth Surfaces over C, one of the most beautiful and deepest contributions of early twentieth century algebraic geometry. The theorem states the equality of two apparently different birational invariants associated with the surface $F$ : the dimension of the space of closed holomorphic 1 -forms on $F$ (called Picard integrals of the first kind) and the irregularity $q \equiv p_{g}-p_{a}$ of $F$, where $p_{g}$ is the geometric genus and $p_{a}$ is the arithmetic genus of $F$. See, e.g., [Kl 05, pp. 243-244] for a more thorough discussion of this theorem, including the relative contributions of the two mathematicians.

Principle of the Conservation of Number and Enumerative Geometry. Severi in 1912 made an exhaustive analysis of the validity of the Principle of the Conservation of Number, a very important tool in enumerative geometry [Sev 12]. However, he did this utilizing the foundational language and tools available in 1912. Further progress required a more refined foundational language, which indeed evolved in the following decades and consequently led to significant additional progress in enumerative geometry and Schubert's calculus (Hilbert's 15 th problem). See [Kl 76] for a definitive history, including Severi's contributions.

Rational Equivalence of Algebraic Cycles and Intersection Theory on Smooth Projective Varieties over C. Severi's contributions here consist both of deep insights and serious missteps. He first introduced the notions of rational equivalence of algebraic cycles and studied its relationship to the intersection of algebraic cycles [Sev 33]. Early on, he became aware of difficulties with his definition of rational equivalence and its relationship to the intersection theory of algebraic cycles, and as a result, he continued to modify his definitions as time went on. At the 1954 International Conference of Mathematicians (as related by B. L. van der Waerden), Severi presented a new exposition of his theory, which Andre Weil famously (and correctly) criticized in the discussion session. Subsequently, in 1970 van der Waerden [Waer 70] ${ }^{9}$ showed to his satisfaction that Severi's definitions and results could in fact be adjusted to meet the modern standards of rigor. Precise and satisfactory definitions of rational equivalence in the rigorous language of the "French" school were given independently. See, e.g., Claude Chevalley [Chev 58]. To summarize the significance of Severi's contributions to rational equivalence and intersection theory, we

\footnotetext{
${ }^{9}$ There were many exchanges over the years between Severi and van der Waerden concerning various aspects of algebraic geometry, including rational equivalence. For a description of some of these interactions, see the fascinating article by Norbert Schappacher [Sch 07].
} 


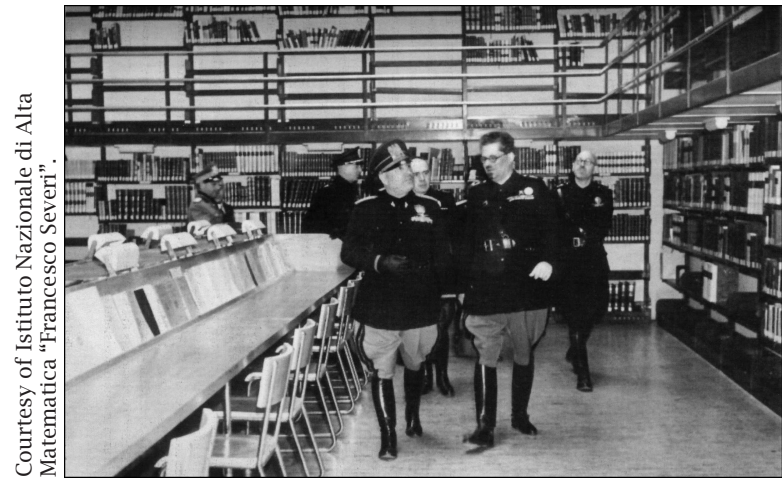

Benito Mussolini and Francesco Severi (on the right) in the University of Rome's mathematics library, 1939.

turn to William Fulton [Ful 98, pp. 25-26], who, in his authoritative work on the subject, wrote: "It would be unfortunate, however, if Severi's pioneering work in this area were forgotten; and if incompleteness and the presence of errors are grounds for ignoring Severi's work, few of the subsequent papers on rational equivalence would survive."

\section{Some Severi Conjectures}

In addition to the multitude of theorems Severi claimed to have proved, he also made many interesting conjectures, some true, some false, including the examples below. Both of these conjectures have been settled-one as true, the other false-in two well-known papers of Kodaira [Kod 52] and Mumford [Mum 69].

Conjecture 1. Let $V$ be a smooth irreducible projective variety of dimension $n$. In [Sev 09], Severi conjectured that

$$
p_{a}=g_{n}-g_{n-1}+g_{n-2}-\cdots(-1)^{n-1} g_{1},
$$

where $p_{a}$ is the arithmetic genus of $V$ and $g_{j}$ is the dimension of the vector space of holomorphic $j$-forms on $V$. This was proved by Kodaira in 1954 .

Mumford proved the following conjecture of Severi to be false.

Conjecture 2. Let $F$ be a smooth surface over $\mathbf{C}$. Then the group of 0 -cycles modulo rational equivalence is finite dimensional.

Ironically, paraphrasing Mumford, the method of disproof of this conjecture is based almost entirely on Severi's systems of equivalence.

For an excellent discussion of this conjecture and several other related topics that Severi explored, see the article by A. Brigaglia, C. Ciliberto, and Claudio Pedrini [B-C-P 04]. Interestingly, they describe some of Severi's work, starting with his theory of rational equivalence in 1932, that has proved to be relevant to the study of motives, an important topic of current interest in algebraic geometry.

\section{Acknowledgments}

We thank Maryse Bowers, who translated key passages of Severi's letter to Boas; William Fulton for his helpful comments; Elisa Piccio, Annalisa Capristo, and Giorgio Fabre for their friendship; Ivo Biagianti and Italo Farnetani for useful discussions in Arezzo; Francesca Rosa for archival research in Rome and Michelle Frankfort for tracking down documents in the Zariski Papers; Rita Zanatta, Susanna Panetta, Alessandro Romanello, Charlotte Erwin, and the staffs at the Archivio Centrale dello Stato (EUR), the Archivio Storico della Sapienza, Università di Roma, the Istituto storico italiano per il medioevo, the Accademia Nazionale dei Lincei, Harvard University Archives, and the California Institute of Technology Archives for their help and permission to quote from materials in their repositories. Heidi Aspaturian provided valuable editorial advice and assistance.

\section{References}

[B-G 10] D. BABвitT and J. Goodstein, Federigo Enriques's quest to prove the "Completeness Theorem", Notices Amer. Math. Soc. 58 (2010), 240-248.

[B-C 95] A. BRIGAGLIA and C. Ciliberto, Italian Algebraic Geometry between the Two World Wars, transl. from the Italian by J. Duflot, Queen's University, Kingston, 1995.

[B-C-P 04] A. Brigaglia, C. Ciliberto and C. Pedrini, The Italian school of algebraic geometry and Abel's legacy, in The Legacy of Niels Henrik Abel, Olav A. Laudal and Ragni Piene, eds., Springer-Verlag, Berlin/Heidelberg, 2004, pp. 295-347.

[Bo 05] R. J. B. BosworTH, Mussolini's Italy: Life under the Fascist Dictatorship, 1915-1945, Penguin Group, New York, 2005.

[Cap 03] A. CAPRISTO, Tullio Levi-Civita e l'Accademia d'Italia, La Rassegna mensile di Israel 69 (2003), 237-56.

[Chev 58] C. Chevalley, Les classes d'équivalence rationelle I, II, Séminaire C. Chevalley $2^{e}$ année, in Anneaux de Chow et Applications, École Normale Supérieure, Paris, 1958.

[Fabre 08] G. FABRE, I volenterosi collaboratori di Mussolini, Un caso di Antisemitismo del 1931, Quaderni di storia 68 (2008), 89-122.

[Good 84] J. GoodsteIN, The rise and fall of Vito Volterra's world, J. Hist. Ideas 45 (1984), 607-617.

[Gowers 08] T. GowERs, ed., The Princeton Companion to Mathematics, Princeton University Press, Princeton, 2008.

[G-N 05] _ Italian Mathematics between the Two World Wars, Birkhäuser Verlag, Basel, 2005. 
[Ful 98] W. Fulton, Intersection Theory, 2nd ed., Springer-Verlag, New York, 1998.

[Ha 86] J. HARRIS, On the Severi problem, Invent. Math. 84 (1986), 445-461.

[Kl 76] S. L. KLEIMAN, Rigorous foundation of Schubert's enumerative calculus, Proc. of Symposia in Pure Math. 28, Amer. Math. Soc., Providence, RI, 1976, pp. 445-482.

[Kl 05] _ The Picard scheme, Math. Surveys and Monographs 123, Amer. Math. Soc., 2005, pp. 237-331.

[Kod 52] K. KODAIRA, Arithmetic genera of algebraic varieties, Proc. Nat. Acad. Sci. U.S.A. 38 (1952), 527-533.

[Laz 81] R. LAZARSFELD, Excessive intersection of divisors, Comp. Mathematica 43 (1981), 281-296.

[Mum 69] D. MumFord, Rational equivalence of 0cycles on surfaces, J. Math. Kyoto 9 (1969), 195-204.

[Nér 52] A. Néron, La théorie de la base pour les diviseurs sur les variétés algébriques, Deuxième Colloque de Géométrie Algébrique Liège, Masson \& Cie, Paris, 1952, pp. 119-126.

[Parikh 91] C. PARIKH, The Unreal Life of Oscar Zariski, Academic Press, Boston, 1991.

[Rog 05] GiNo Roghi, "Materiale per una Storia dell'Istituto Nazionale di Alta Matematica dal 1939 al 2003", serie La Matematica nella Società e nella Cultura, Bollettino U.M.I., Bologna, Serie VIII, Vol. VIII-A, Dicembre 2005/2.

[Roth 63] L. Roth, Francesco Severi, J. London Math. Soc. 38 (1963), 282-307.

[Sch 07] N. SCHAPPACHER, A historical sketch of B. L. van der Waerden's work in algebraic geometry: 1926-1946, Jeremy J. Gray and Karen Hunger Parshall, eds., in Episodes in the History of Modern Algebra (1800-1950), American Math. Soc., Providence, 2007, pp. 245-283.

[Segre 62] L L'opera scientifica di Francesco Severi, Rend. Mat. (5) 21 (1962), 524-584.

[Sev 05] F. SEveri, Sulla differenza fra i numeri degli integrali di Picard della prima e della seconda specie appartenenti ad una superficie irregolare, Atti Acc.Torino 40 (1905), 288-296.

[Sev 06] Sulla totalità delle curve algebriche tracciate sopra una superficie algebrica, Math. Annalen 62 (1906), 194-225.

[Sev 09] _ _ Fondamenti per la geometria sulla varietà algebriche, Rend. del Circolo Matematico di Palermo 28 (1909), 33-87.

[Sev 12] _ Sul principio della conservazione del numero, Rend. del Circolo Matematico di Palermo 33 (1912), 313-327.

[Sev 33] _ U Über die Grundlagen der algebraischen Geometrie, Abhandlungen aus dem math. Seminar der Hamsburgischen Universität 9 (1933), 335-364.

[Sev 49] _ La géométrie algébrique italienne: sa rigour, ses méthodes, ses problèmes, in Colloque de géométrie algébrique, Liège, 1949, Misson et Cie, Paris, 1950, pp. 9-55.
[Sev 60]

Fondamenti della Geometria sulle varietà algebriche, Annali di Matematica, 49 (1960), 283-298.

[Waer 70] B. L. VAN DER WAERDEN, The theory of equivalence systems of cycles on a variety, 1971 Symposia Mathematica, INDAM, Rome, 1969/70), Academic Press, London, pp. 255-262.

[Ves 90] E. VesEnTINI, Il caso della Matematica, Consequenze culturali delle leggi razziali in Italia, Accademia Nazionale dei Lincei, Rome 84 (1990), 97-105.

[Zar 71] O. ZARISKI, Algebraic Surfaces (second supplemented ed.), Springer-Verlag, New YorkHeidelberg, 1971.

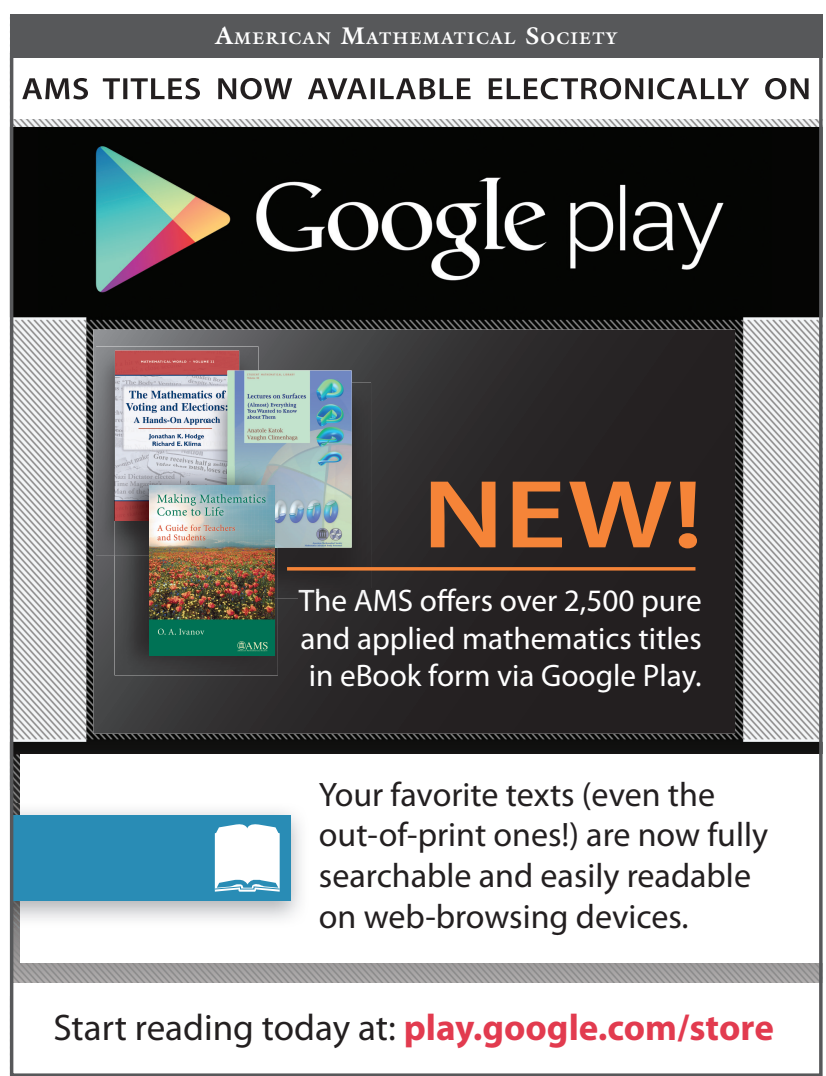

